\title{
EDUCAÇÃO ESCOLAR DE JOVENS E ADULTOS PRIVADOS DE LIBERDADE: Realidade Brasileira e Panorama Legal
}

\author{
http://dx.doi.org/10.21527/2176-6622.2019.51.88-99
}

Recebido em: 1으/2018

Aceito em: 19/5/2019

Lucas Andres Arbage

Mestrado em Educação pela Universidade Federal da Fronteira Sul (UFFS). Especialização em Direito Penal e Processo Penal e em Direito Civil e Empresarial - Faculdade de Direito Damásio de Jesus. Graduação em Direito pela Faculdade Metodista de Santa Maria - Fames. Advogado (OAB n. 40.125 OAB/SC).

\section{RESUMO}

Este artigo tem como problema de pesquisa a ausência de políticas governamentais educativas dos apenados, as quais serviriam para a redução da desigualdade social e de renda da sociedade brasileira. O objetivo geral é conjecturar acerca da (não)atuação estatal ante a temática da educação de jovens e adultos privados de liberdade no contexto brasileiro. Os objetivos específicos são: discorrer acerca da legalidade da educação para jovens e adultos privados de liberdade, detectar os motivos pelos quais isso (não)acontece e ponderar acerca da pertinência de uma política pública voltada para esta finalidade. No desenvolvimento do artigo, constatou-se a pequena oferta de processos educativos nas instituições de privação de liberdade e a precariedade do sistema prisional brasileiro, consubstanciada pelo aumento no número geral de presidiários, pelos altos índices de reincidência no cometimento de crimes e pelas condições sub-humanas presenciadas nestas localidades. A conclusão é de que o atual contexto colabora para o aumento e perpetuação da desigualdade social, uma vez que reflete poucas oportunidades de reintegração social do apenado. Para mudar a atual realidade, é fundamental a implementação de uma política pública estatal para instituir os referidos processos educativos, compreendendo-se a educação como direito humano, investindo em suas esferas escolares e não escolares, a fim de cumprir a lei e proporcionar uma oportunidade aos jovens e adultos privados de liberdade. A metodologia empregada foi a pesquisa bibliográfica e documental, composta pela análise de documentos oficiais, do ordenamento jurídico e doutrina.

Palavras-chave: Direito penal. Direitos humanos. Garantismo. Políticas públicas. Reintegração social.

\section{SCHOOL EDUCATION OF YOUNG PEOPLE AND PRIVATE ADULTS OF FREEDOM: BRAZILIAN REALITY AND LEGAL OVERVIEW}

\section{ABSTRACT}

This article has as a research problem the lack of governmental educational policies of the victims, which would serve to reduce the social and income inequality of Brazilian society. The general objective is to conjecture about the (non)state action on the issue of the education of youths and adults deprived of liberty in the Brazilian context. The specific objectives are: to discuss the legality of education for young people and adults deprived of their liberty, to detect the reasons why this does not happen and to consider the pertinence of a public policy aimed at this purpose. In the development of the article, there was a small supply of educational processes in institutions of deprivation of liberty and the precariousness of the Brazilian prison system, consubstantiated by the increase in the general number of prisoners, by the high rates of recidivism in the commission of crimes and by the sub conditions -humans witnessed in these localities. The conclusion is that the current context contributes to the increase and perpetuation of social inequality, since it reflects few opportunities for social reintegration of the distressed. To change the current reality, it is essential to implement a state public policy to institute such educational processes, including education as a human right, investing in its school and non-school spheres, in order to comply with the law and provide an opportunity young people and adults deprived of their liberty. The methodology used was the bibliographical and documentary research, composed by the analysis of official documents, of the legal order and doctrine.

Keywords: Criminal law. Human rights. Garantism. Public policy. Social reintegration.

\section{SUMÁRIO}

1 Introdução. 20 sistema prisional brasileiro. 3 A Educação de Jovens e Adultos privados de liberdade como política pública. 4 Considerações finais. 5 Referências. 


\section{INTRODUÇÃO}

Na sociedade moderna a prisão é a principal forma de punição prevista junto ao sistema de execução penal, em que a restrição dos direitos e da liberdade da pessoa é compatibilizada e proporcional à sua conduta entendida como criminosa e às condições pessoais e do caso concreto que ocasionou a demanda judicial e consequente encarceramento.

Para determinados setores populacionais, nos últimos anos, com a modernização e o êxodo rural, aflorou-se a pobreza, marginalização e a desigualdade social, características tristes, mas tradicionais do Brasil, gerando nefastas consequências para a sociedade brasileira. Sob este cenário, de acordo com o documento oficial mais recente sobre o tema, qual seja, Levantamento Nacional de Informações Penitenciárias - Infopen, com publicação em dezembro de 2017, mas dados relativos ao ano de 2016 -, é pertinente frisar que na sociedade brasileira os crimes patrimoniais relacionados a furto e roubo correspondem a $37 \%$ das incidências penais pelas quais as pessoas privadas de liberdade foram condenadas ou aguardam julgamento (BRASIL, 2017, p. 43).

Dentre os diversos problemas gerados por esta situação, destaca-se o crescimento da criminalidade e do número de pessoas encarceradas. $O$ crescimento do poder punitivo é propagado no Brasil principalmente pela política pública de guerra às drogas, a qual objetiva transmitir o pensamento de que "bastaria prender os envolvidos com as drogas, que o problema estaria resolvido". A proibição às drogas alude à criminalização de condutas que, ainda que sejam realizadas amplamente em variados locais do mundo, facilitam a edição de fantasias e a criação de cruzadas moralizadoras (DARKE; KARAM, 2016).

Resumidamente, os resultados da referida política pública são: índices crescentes de encarceramento, gerando números gerais nunca vistos antes de pessoas privadas de liberdade; alta reincidência no cometimento de crimes; precária infraestrutura das instituições prisionais; ausência de políticas públicas que objetivem diminuir a reincidência e o cometimento de crimes.

A partir dos números fornecidos pelo Infopen, denota-se que a população de pessoas privadas de liberdade no Brasil é a terceira maior do mundo, somente tendo menor número do que os Estados Unidos e a China. Enquanto, todavia, nestes outros dois países o número total de encarcerados tem diminuído nos últimos anos, no Brasil a situação é inversa. Como se não bastasse, o Brasil apresenta índice de reincidência no cometimento de crimes de cerca de $80 \%$ dos egressos do sistema carcerário.

Diante deste contexto, surge o questionamento óbvio: $\mathrm{O}$ que deve ser feito e como proceder com o indivíduo que cometeu algum delito e encontra-se cumprindo pena preso?Pelo Infopen, obteve-se a informação da escolaridade de $70 \%$ da população privada de liberdade no Brasil -482.645 pessoas. Mantendo a tendência de pesquisas anteriores, observa-se um baixo grau de escolaridade, posto que $75 \%$ desta população sequer acessou o Ensino Médio, concluindo, no máximo, o Ensino Fundamental (BRASIL, 2017, p. 34).

Neste cenário, é importante considerar que existe proposta de alteração da Constituição Federal acerca da redução da maioridade penal para 16 anos, que é a Proposta de Emenda à Constituição - PEC 171/1993 -, o que agravaria, em sendo aprovada, a problemática da baixa escolaridade desta população de pessoas privadas de liberdade, o que, por sua vez, deflagra a importância de existir uma política pública de educação para essa camada populacional.

Tendo em vista que a educação é considerada, por muitos, como base para um desenvolvimento mais equilibrado do ser humano, uma das alternativas para modificação deste quadro crescente do número de apenados e de falência dos sistemas prisionais, dar-se-ia por meio do processo de "reeducação social" da população apenada por meio, exatamente, do acesso e frequência a processos educativos, formais e informais.

Com isso, se conferiria um tratamento mais digno e humano para essa parcela da população, uma vez que, atualmente, as notícias vinculadas ao sistema carcerário são somente no sentido de que as prisões são, via de regra, instituições que especializam o apenado para o cometimento de crimes, contribuindo para que este passe a integrar facções criminosas e saia da prisão mais violento e especializado no cometimento de crimes. A fim de ilustrar e comprovar a falência do sistema prisional brasileiro, destaca-se que somente no primeiro mês do ano de 2017, em rebeliões ocorridas em Manaus, Rio Grande do Norte e Roraima, mais de cem apenados foram executados dentro das instituições prisionais. 
A partir desse contexto, o presente artigo tem como objetivo principal debater a (não)atuação estatal ante a temática da educação de jovens e adultos privados de liberdade no contexto brasileiro. Parte-se de uma análise do sistema prisional do Brasil, concluindo que a instituição de processos educativos nas prisões pode ser uma alternativa de reintegração social do apenado. Prossegue-se com uma apreciação conceitual do Estado e suas responsabilidades, concluindo-se pela necessidade de se instituir uma política pública destinada a assegurar e conferir a ampla abrangência que a temática demanda.

O trabalho é condensado mediante abordagem qualitativa, do tipo exploratória, com instrumento de aplicação à pesquisa documental e bibliográfica.

A pertinência do assunto configura-se pela possibilidade de aprofundar o estudo acerca das questões educacionais, das inovações no âmbito da educação e da afinidade com as extensões sociais, culturais e políticas, na tentativa de convidar os envolvidos com o direito, a educação e a sociedade para uma reflexão sobre como o acesso a aspectos educativos por parte dos apenados pode contribuir para que os mesmos tenham mais condições de se reintegrarem socialmente, para que sobrevenha uma sociedade com menos desigualdade.

Entende-se que a temática é instigante e pertinente por se tratar de direito negligenciado e/ou não efetivado que atinge significativa parcela populacional, e pelo caráter social/humano que a reflexão detém.

\section{O SISTEMA PRISIONAL BRASILEIRO}

O sistema prisional brasileiro, amparado na legislação e, ao menos na teoria, tem como finalidade, além da punição para quem cometeu algum crime, sua ressocialização e/ou reintegração social. Para efetivar a punição, o Estado assume a responsabilidade de combater os crimes, e a principal medida coercitiva e punitiva existente é a prisão.

No momento em que a pessoa assume a condição de estar privada de sua liberdade, tendo sua vida e liberdade tuteladas pelo Estado, recuperá-lo deveria ser um, senão o principal, objetivo de quem figura como responsável e zela por sua vida, ou seja, o Estado, o qual, inclusive, não pode se desincumbir desta responsabilidade.

O sistema prisional brasileiro encontra-se em um estado lastimável, seja pela precariedade dos serviços (não)prestados, pela superlotação ou pelas inúmeras violações aos direitos humanos constatadas nas instituições prisionais. Neste sentido, Rafael Damasceno de Assis $(2007$, p. 1) elucida que "[...] acaba ocorrendo é uma dupla penalização na pessoa do condenado: a pena de prisão propriamente dita e o lamentável estado de saúde que ele adquire durante a sua permanência no cárcere".

Inexiste informação oficial e segura acerca do índice exato de reincidência no cometimento de crimes de egressos do sistema prisional brasileiro, existindo somente alguns levantamentos que podem ser utilizados como base a fim de aferir esse índice, como o relatório da Comissão Parlamentar de Inquérito (CPI) do sistema carcerário, que divulgou, em 2008 , que essa taxa era alta e ficava entre $70 \%$ ou $80 \%$, variando de acordo com o Estado analisado.

De acordo com o Infopen (BRASIL, 2017), atualmente o Brasil é o terceiro país com mais presos no mundo. Quanto ao número de presidiários, no ano de 2015 o Brasil apresentava 698,6 mil, e no referido ano acabou ultrapassando o então terceiro país com mais presidiários no mundo, que era a Rússia, com 646,1 mil, ficando atrás somente dos Estados Unidos, com 2,14 milhões e China, com 1,65 milhão.

É interessante e triste detectar, ainda, que, dentre estes países supracitados, exceto o Brasil, todos estão diminuindo a população de presidiários, com o que, mantendo-se o atual ritmo, logo o Brasil ultrapassará a China e será o segundo país que mais prende pessoas no mundo. Trata-se, por conseguinte, de crescimento populacional em grau assustador e que não é presenciado em qualquer outro país do mundo, culminando com uma imensa população prisional. Além disso, é importante destacar que em números gerais a China, por exemplo, apresenta número populacional muito maior do que o Brasil, portanto, proporcionalmente, aqui há muito mais pessoas encarceradas.

O último documento oficial que realizou comparativo entre a população prisional dos países foi o Infopen do ano de 2014, relativo a dados obtidos até dezembro de 2013. Nesse documento, verifica-se que, entre os anos de 2008 e 2013, os Estados Unidos diminuíram a taxa de pessoas presas de 755 para 698 para cada cem mil habitantes (-8\%). A China reduziu, no mesmo tempo, de 131 para 119 a taxa (-9\%). A Rússia, por 
sua vez, diminui em $24 \%$ a taxa de pessoas presas para cada cem mil habitantes. De outro norte, o Brasil é o único dentre os quatro países que mais encarceram no mundo, cuja taxa aumentou no referido período (33\%) (BRASIL, 2014, p. 14).

Contextualizando e comparando o sistema prisional brasileiro com o dos 20 países com maior população carcerária, verifica-se que a taxa de aprisionamento da população prisional brasileira era a quarta maior: somente os Estados Unidos, a Rússia e a Tailândia tinham um contingente prisional mais elevado. A taxa de ocupação dos estabelecimentos prisionais brasileiros (161\%) era a 5 a maior entre os países em voga. As Filipinas (316\%), o Peru (223\%) e o Paquistão (177\%) têm a maior taxa de ocupação prisional (BRASIL, 2014, p. 1213). Existe, todavia, levantamento nacional de informações mais recente, que não realizou o comparativo com outros países, mas aferiu que a atual taxa de ocupação no sistema prisional brasileiro, em junho de 2016, não incluindo as informações do Sistema Penitenciário Federal, era de 197,8\%, o que já faria sermos o quarto pior país do mundo nesse quesito (BRASIL, 2017, p. 26). Ou seja, a situação está ruim e piorando.

Entre os anos de 1995 e 2010 o Brasil, dentre os 50 países com maior população prisional, apresentou a segunda maior variação na taxa de aprisionamento, com aumento na porcentagem de $136 \%$. Somente a Indonésia mostrou ritmo de crescimento da população prisional maior que o do Brasil. Do número total de presidiários, no entanto, a Indonésia apresenta cerca de $70 \%$ a menos do que o número total de presidiários no Brasil (BRASIL, 2014, p. 14).

No período compreendido entre os anos 2000 e 2016, a população prisional aumentou, em média, 7,3\% ao ano, passando de 232 mil pessoas em 2000 para 726 mil pessoas privadas de liberdade em 2016. Isto significa um aumento dez vezes maior que o geral da população brasileira, que apresentou aumento total de apenas 16\% no período, em uma média de cerca de 1\% ao ano (BRASIL, 2017, p. 20). Quanto às instituições prisionais e o gênero a que se destinam, $75 \%$ dos estabelecimentos é destinado ao gênero masculino, $17 \%$ têm destinação mista e $7 \%$ destinação feminina.

Chegando-se aos dias atuais, essa situação de crescimento da população de pessoas privadas de liberdade no Brasil se agrava, uma vez que o Conselho Nacional de Justiça - CNJ -, por meio de seu site, disponibiliza a informação acerca de quantos mandados de prisão estão expedidos e pendentes de cumprimento, posto que no dia 23/4/2018 esse número chega a quantia de 610.206. Ou seja, somando-se os mandados de prisão com o número de pessoas que já estão presas, o Brasil fica muito próximo de ser o segundo país com mais presidiários do mundo.

A informação quanto à faixa etária da população prisional trata-se de uma estimativa, uma vez que se obteve a informação de apenas $75 \%$ da população prisional, ou seja, 514.987 pessoas. A partir da análise da amostra de pessoas sobre as quais foi possível obter dados acerca da idade, pode-se afirmar que $55 \%$ da população prisional é formada por jovens, considerados até 29 anos, segundo classificação do Estatuto da Juventude, Lei no 12.852/2013 (BRASIL, 2017, p. 30).

Outra questão que se constata é a de que o sistema prisional trata, via de regra, o negro de maneira discriminatória. A cada três presos, cerca de dois são negros. A informação sobre a raça, cor ou etnia da população prisional estava disponível para 493.145 pessoas (ou $72 \%$ da população prisional total). A partir da análise da amostra de pessoas sobre as quais foi possível obter dados acerca da raça, cor ou etnia, pode-se afirmar que $64 \%$ da população prisional é composta por pessoas negras. Na população brasileira acima de 18 anos, em 2015, a parcela negra representa 53\% (BRASIL, 2017, p. 32).

O grau de escolaridade da população prisional brasileira é baixo e significativamente inferior à média de brasileiros que não estão encarcerados. Foram obtidas informações acerca da escolaridade para $70 \%$ da população privada de liberdade no Brasil, isto é, 482.645 pessoas. Nessa amostra, observa-se o baixo grau de escolaridade, seguindo a tendência já expressa em levantamentos anteriores. Constata-se que $75 \%$ da população prisional brasileira ainda não acessou o Ensino Médio, tendo concluído, no máximo, o Ensino Fundamental (BRASIL, 2017, p. 34).

Além disso, como já destacado, os crimes patrimoniais assumem grande relevância no número total de presidiários no Brasil, podendo-se concluir que a desigualdade social e de distribuição de renda, as quais são sabidas que ocorrem em grandes proporções no Brasil, contribuem com o crescimento da criminalidade. 
Está previsto na Lei de Execução Penal o acesso à assistência educacional, sendo um direito garantido à pessoa privada de liberdade, que deve ser ofertado pelo Estado na forma de instrução escolar e formação profissional, objetivando a reintegração da população prisional à sociedade.

Para aferir a questão das atividades educacionais, foram discriminadas entre atividades de ensino escolar, que compreendem as atividades de alfabetização, formação de Ensino Fundamental até Ensino Superior, cursos técnicos (acima de 800 horas de aula) e curso de formação inicial e continuada (capacitação profissional, acima de 160 horas de aula); e atividades complementares, que compreendem as pessoas matriculadas em programas de remição pelo estudo por meio da leitura, pessoas matriculadas em programas de remição pelo estudo por meio do esporte e pessoas envolvidas em demais atividades educacionais complementares (BRASIL, 2017, p. 53).

Somente $12 \%$ da população prisional no Brasil está envolvida em algum tipo de atividade educacional, entre aquelas de ensino escolar e atividades complementares (BRASIL, 2017, p. 53).

Mediante a exposição do panorama geral do sistema prisional brasileiro, constata-se a gravidade e pertinência da discussão de como proceder com o indivíduo que cometeu um delito, pois atualmente é flagrante a fragilidade nas tentativas de recuperação e reintegração social dos presidiários, o que contribui para o crescimento da criminalidade, da população carcerária e das desigualdades sociais. Assim, entende-se que uma das alternativas para alteração desse quadro caótico do sistema prisional é a possibilidade de que os apenados tenham acesso e frequência a processos educativos, começando-se este processo ainda no período em que os mesmos estão cumprindo pena e se encontram na condição de presidiários.

\section{A EDUCAÇÃO DE JOVENS E ADULTOS PRIVADOS DE LIBERDADE COMO POLÍTICA PÚBLICA}

O direito à educação integra o rol dos direitos fundamentais previstos junto ao artigo 50 da Constituição Federal de 1988 - CF/88. Neste sentido, flagrante é a importância conferida pelo legislador à educação, quando a enquadra e positiva como direito fundamental de todos os brasileiros.

A positivação e previsão como sendo um direito do cidadão - seja da educação ou da saúde, por exemplo - é fundamental para que se tenha condições de pleitear com mais segurança a efetivação destas garantias asseguradas legalmente, pois, pela positivação se estabelecem os limites, possibilidades, modalidades e as próprias regras que a educação deve se pautar, tanto pela CF/88quanto pela Lei de Diretrizes e Bases da Educação Nacional, no 9.394/1996 - LDB - ou por meio de outros dispositivos legais.

Além de a educação ser um direito do cidadão brasileiro, é definida como obrigação do Estado. Do direito nascem as prerrogativas das pessoas, em razão das quais passam a gozar de algo que lhes pertence como tal. Do dever nascem as obrigações que necessitam ser respeitadas, seja por quem tem a responsabilidade de assegurar o direito, como o Estado e seus representantes, ou por parte de outros sujeitos implicados nessas obrigações (CURY, 2005).

Ao definir um direcionamento sintético acerca das diretrizes da educação brasileira, a CF/88 disciplina, em seu artigo 205, que é um requisito para a cidadania dos cidadãos brasileiros. Além disso, o artigo 60 da CF/88 define a educação como um direito social do cidadão. A educação é assim definida no sentido de promover condições para que o cidadão evolua tanto como pessoa quanto profissionalmente, adquirindo as condições básicas a fim de viver em sociedade. A educação, portanto, constitui um direito social, de maneira que o Estado deverá assegurar a todos o seu acesso, ante a relevância e pertinência que apresenta para o desenvolvimento equilibrado do ser humano.

É consenso que o princípio da dignidade da pessoa humana é um dos mais relevantes do Estado Democrático de Direito. Esta importância é comprovada, uma vez que os direitos sociais, expressos junto ao artigo 60 da CF/88 - como direito à saúde, segurança, assistência aos desamparados e trabalho -, estão intimamente ligados à dignidade da pessoa humana. Na esfera internacional, destaca-se a Declaração Universal dos Direitos Humanos, que, no artigo 26, prevê o direito à educação, com o objetivo do pleno desenvolvimento da pessoa e o fortalecimento do respeito aos direitos humanos.

Comprova-se a importância que o Brasil confere aos direitos humanos, posto que ratificou o Pacto Internacional dos Direitos Civis e Políticos e o Pacto Internacional dos Direitos Econômicos, Sociais e Culturais, os quais o inserem no Sistema Internacional de Proteção dos Direitos Humanos. 
É fundamental salientar que os direitos humanos apresentam diferente valoração de acordo com a região, ante a sua cultura e hábitos, por exemplo. É esse o entendimento de Arbage e Da Costa Vasconcellos (2017, p. 21-22):

Aqui é importante destacar que a compreensão do que abarca os direitos humanos pode variar de um país para outro. Todavia, em que pese existir essa referida distinção quanto à extensão dos direitos humanos, é inegável que a possibilidade de ofertar educação está enquadrada como uma política pública efetiva, necessária e indispensável a todos os países, alinhando-se no sentido de ser um meio de promoção da vida com dignidade e com possibilidade de diminuição da desigualdade social.

Ainda que exista a referida variação quanto à extensão dos direitos humanos, é uníssono o entendimento que proporcionar a possibilidade de acessar a processos educativos é primordial e essencial em qualquer sociedade, no intuito de proporcionar o desenvolvimento do cidadão. Destaca-se que a educação aqui abordada e defendida para ser instituída para as pessoas privadas de liberdade, é compreendida como além do processo educativo institucionalizado, também denominado de educação formal, acrescentando-se neste contexto as experiências educativas que acontecem no cotidiano das pessoas, por meio do relacionamento com outros cidadãos e com seu próprio ambiente.

No contexto nacional, a CF/88 estabelece como princípio do ensino a garantia de um padrão de qualidade (artigo 206, VII), advertindo, ainda, que o não oferecimento do ensino obrigatório ou sua oferta irregular, importa responsabilidade da autoridade competente (artigo 208, § 2ㅇ).

Atualmente, portanto, se constata que o Estado tem a obrigatoriedade/dever de fornecer educação ao menos até o nível de Ensino Médio, sem distinção de gênero, sexo ou raça. Neste sentido, surge a dúvida e inquietação: $O$ apenado também tem direito à educação?

Existe o direito ao acesso à educação pelo apenado, estando o mesmo positivado junto a Lei de Execução Penal - LEP, no 7.210/1984 -, por intermédio da qual se define os caminhos pelos quais se buscará sua reintegração social. Acerca da responsabilidade pelo apenado, a lei é clara, imputando a mesma ao Estado, artigo 10 da LEP, posto que sua assistência educacional está prevista no artigo 11, IV, também da LEP.

A fase da execução da pena pode ser entendida como fase autônoma e com peculiaridades distintas, tanto do Direito Penal quanto do Código de Processo Penal. Deverá respeitar, todavia, e estar de acordo com vários direitos e garantias fundamentais, assegurando-se o devido processo legal e o respeito à LEP.

Mesmo, portanto, após o trânsito em julgado de sentença condenatória e no cumprimento da pena, o apenado é titular de todos os direitos claramente positivados e, neste sentido, é importante destacar que existe uma seção inteira para tratar sobre sua assistência educacional, seção $\mathrm{V}$, indo do artigo 17 até o artigo 21-A da LEP.

Quanto aos níveis de ensino e sua obrigatoriedade, constata-se que o Ensino Fundamental é um direito juridicamente protegido desde 1934, sendo considerado direito público subjetivo a partir da promulgação da $\mathrm{CF} / 88$, obrigatório para pessoas de 7 a 14 anos e gratuito, posto que na eventualidade de inexistência de vaga para cursar esta etapa de ensino, pode-se pleiteá-la perante o Poder Judiciário. Já o Ensino Médio se constata como obrigatório somente a partir da Lei no 13.163, de 2015, mediante alteração na Lei de Execuções Penais LEP, com a introdução do artigo 18-A.

Mediante a Emenda Constitucional no 59, estendeu-se a obrigatoriedade do Estado no que se refere à oferta de Educação para os cidadãos brasileiros, passando a vigorar a seguinte alteração legal no artigo 208, I, CF/88: "educação básica obrigatória e gratuita dos 4 (quatro) aos 17 (dezessete) anos de idade". Destaca-se, ainda, que a oferta abarca também cidadãos que não tiveram acesso ao ensino na idade correta. Por conseguinte, atualmente o Estado tem a obrigação de oferecer educação até o Ensino Médio, ainda que os cidadãos já tenham ultrapassado a idade correspondente para cursar esta etapa de ensino.

Assim, verifica-se que não somente existe a previsão legal da educação de pessoas privadas de liberdade, como a mesma se apresenta como um dever do Estado para com o presidiário. Sobre isso, Cury (2002, p. 249) afirma que: 
Em todo o caso, a ligação entre o direito à educação escolar e a democracia terá a legislação como um de seus suportes e invocará o Estado como provedor desse bem, seja para garantir a igualdade de oportunidades, seja para, uma vez mantido esse objetivo, intervir no domínio das desigualdades, que nascem do conflito da distribuição capitalista da riqueza, e progressivamente reduzir as desigualdades.

O direito à educação do apenado, então, estando positivado em lei, inserido na CF/88 e na LDB e, a educação, tendo potencial orientador, formador e transformador dos sujeitos, porque não oferecê-la e proporcioná-la também aos apenados, que constituem uma parcela populacional amplamente desassistida e com baixíssima escolaridade?

$\mathrm{Na}$ realidade brasileira, além da educação de pessoas privadas de liberdade ser pouco difundida nas instituições penitenciárias, ainda se tem estas sendo taxadas de "escolas do crime". Aqui reside uma séria problemática sobre o tema, que é a de modificar um entendimento difundido em nossa sociedade, exemplificado, por exemplo, com a expressão popular: "bandido bom é bandido morto". Deve ocorrer um rompimento paradigmático no que se refere à forma como se encara o sistema prisional e o próprio apenado, mudando-se o discurso e pensamento vingativo e meramente punitivo, passando-se a pensar e tratar o assunto com mais humanidade.

Para que o Estado consiga efetivar e garantir as necessidades básicas de sua população, utiliza-se, dentre outras, as políticas públicas. Neste sentido, destaca-se que deve ser resguardada a igualdade no atendimento destes direitos fundamentais a todos os cidadãos e, por consequência, das políticas públicas, obviamente incluindo aqueles que cumprem pena em instituições prisionais.

Conforme já se destacou, o Brasil apresenta severas desigualdades sociais e de distribuição de renda. Dentro dessa realidade, uma das parcelas populacionais mais desassistidas e em piores condições é a dos apenados. Essa é, portanto, por consequência, uma "camada social" carente e que demanda urgência na adoção de medidas para transformação dessa realidade. Sobre isso, destaca-se que, ainda que a pessoa esteja na condição de presidiário, segue, obviamente, sendo detentora de direitos, e esse é o posicionamento de Arbage e Da Costa Vasconcellos (2017, p. 22):

O indivíduo que se encontra em privação de liberdade é um sujeito de direitos e ainda que tenha cometido um crime, não deixa de integrar a sociedade, tampouco perdeu suas capacidades físicas e intelectuais. Quando se pensa e defende a educação em espaços de restrição de liberdade, é sabido que se trata de um processo complicado de se concretizar, seja pelo preconceito ou pela própria visão que se tem do sistema carcerário, exigindo-se a elaboração e implementação de políticas públicas que possibilitem efetivamente colaborar com a formação de qualidade do apenado para o trabalho, como condição de melhoria de sua vida e de diminuição de reincidência no cometimento de crimes.

Ante a esta problemática, constata-se a gravidade da situação e, em parte, compreende-se o relativamente baixo número de iniciativas que objetivem melhorar a realidade da vida do apenado enquanto presidiário e, depois, na condição de egresso do sistema prisional.

As políticas públicas de educação são legitimadas em razão da previsão legal na esfera nacional e internacional. Todas as pessoas, assim como os indivíduos privados de liberdade, têm direito humano de acesso à educação.

A educação de jovens e adultos privados de liberdade, além de ser um instrumento de reintegração social do mesmo, é um direito fundamental, interligada com a dignidade da pessoa humana, integrando o rol dos direitos humanos e positivada junto aos ordenamentos jurídicos. No momento em que o Estado não fornece educação aos apenados, existe uma falha de ordem moral e também se está descumprindo a lei. 0 direito social dos apenados apenas estará assegurado quando o Estado, ciente de seu dever de lhes fornecer educação, cumprir a lei por meio de uma política pública voltada para esta finalidade, uma vez que o que ocorre atualmente são meras ações esparsas em algumas instituições prisionais.

Políticas públicas são mandamentos finalísticos que visam a concretizar e a fomentar a realização de um direito e que não se instituem automaticamente, pois precisam de um movimento do Estado com a participação da sociedade (ZAGURSKI; KRUBNIKI, 2017, p. 13). 
A política que se pretende analisar pode ser denominada política criminal ou política criminal educativa, dentre outras designações, sendo um aspecto dentre os existentes na política de segurança pública, que, como é sabido, consubstancia-se numa tarefa do Estado. O pleito pela educação para pessoas privadas de liberdade, que da mesma maneira é tarefa do Estado, também pode ser enquadrada como política pública. Bucci $(2006$, p. 3) esclarece que

políticas públicas é o programa de ação governamental que resulta de um processo ou conjunto de processos juridicamente regulados - processo eleitoral, processo de planejamento, processo de governo, processo orçamentário, processo legislativo, processo administrativo, processo judicial - visando coordenar os meios à disposição do Estado e as atividades privadas, para a realização de objetivos socialmente relevantes e politicamente determinados.

Sinteticamente se entende por política pública, em apartada síntese e no contexto abordado no trabaIho, como o Estado inserindo um projeto de governo por intermédio de ações voltadas à educação desta parcela populacional ante a responsabilidade que possui.

Desta forma, o Estado possui a tarefa de originar práticas de fortalecimento e controle de políticas públicas no intuito de que os direitos fundamentais e sociais sejam assegurados também para aqueles que estejam cumprindo pena em restrição de liberdade. Estas políticas devem estar presentes e demonstradas no cotidiano de jovens e adultos privados de liberdade, fazendo-se das instituições prisionais um espaço educativo e de instrução, considerando que a população privada de liberdade é uma das populações mais desassistidas.

Diante das especificidades do contexto, Maeyer (2011) destaca que a educação prisional deve acontecer em uma perspectiva humanista, superando o período do encarceramento, compreendida como algo sequencial e com um olhar coeso com os direitos dos aprisionados, com amplo alcance, não somente para o momento de privação de liberdade. Rangel (2009, p. 111) igualmente entende que:

Las políticas públicas de educación en las prisiones deben valorar las experiencias, expectativas y esfuerzos de las personas en las prisiones. Fomentar el compromiso personal del que habla Mandela es sin duda una misión de los programas educativos en las prisiones. Esto significa valorar el concepto de la educación a lo largo de toda la vida en las prisiones. La persona debe estar al fin de cuentas en el centro de las iniciativas educativas.

A prisão apresenta-se como um espaço não educativo, uma vez que se considera "bom apenado" aquele que respeita as regras e as decisões. A partir desta assertiva, questiona-se: Se o apenado diminui as tomadas de decisão ordinárias sobre seu dia a dia, como se espera que ele, quando em liberdade, seja capaz de fazer isto com naturalidade e adequação?

É neste sentido que a possibilidade de acessar e frequentar a educação se insere como prática emancipadora e capaz de gerar autonomia e cidadania para esse apenado no momento que for (re)inserido na sociedade. Esta inclusão também passa por uma educação permanente de todos aqueles que têm alguma ligação com a prisão.

Nesse sentido, é pertinente discorrer acerca de qual educação se entende que deve ser instituída e aplicada. O que se defende não é "apenas" a possibilidade de acesso à educação sem preocupação com a sua qualidade, somente diminuindo o ócio dos apenados, mas que seja proporcionada uma educação de qualidade, verdadeiramente emancipadora, a fim de que efetivamente possa ocorrer um acréscimo nas formações pessoais e profissionais desses sujeitos. Nesse sentido, é a ideia suscitada por Silva e Braga (2011, p. 371):

A escola nos presídios teria assim uma grande responsabilidade na formação de cidadãos, não só no que diz respeito aos benefícios da instrução escolar e fortalecimento da autoestima dos reclusos, mas, sobretudo, operando a conscientização de direitos e deveres, possibilitando assim um processo de modificação capaz de melhorar a visão de mundo dos prisioneiros através de um senso crítico que auxilie no entendimento do valor da liberdade e do trabalho, na melhoria do comportamento dentro da instituição prisional, e na criação de oportunidades quando do reingresso na sociedade.

A educação defendida para ser instituída é, portanto, uma educação libertadora, como Paulo Freire ensinava. Assim, como o conhecimento é possível na interação comunicativa dos sujeitos, tem-se maiores chances de sucesso no processo educativo, mediado pelo seguinte diálogo intersubjetivo: "ninguém educa ninguém, 
ninguém se educa a si mesmo, os homens se educam entre si, mediados pelo mundo" (FREIRE, 2003, p. 68) este modo, compreende-se a educação como uma tarefa em conjunto entre educador e educando, mediante coparticipação dos sujeitos. Neste sentido, Freire é extremamente claro (2003, p. 68):

A educação libertadora, problematizadora, já não pode ser o ato de depositar, ou de narrar, ou de transferir, ou de transmitir "conhecimentos" e valores aos educandos, meros pacientes, à maneira da educação "bancária", mas um ato cognoscente. Como situação gnosiológica, em que o objeto cognoscível, em lugar de ser o término do ato cognoscente de um sujeito, é o mediatizador de sujeitos cognoscentes, educador, de um lado, educandos, de outro, a educação problematizadora coloca, desde logo, a exigência da superação da contradição educador e educandos. Sem esta, não é possível a relação dialógica, indispensável à cognoscibilidade dos sujeitos cognoscentes, em torno do mesmo objeto cognoscível.

Além disso, é fundamental que ocorra uma educação que, verdadeiramente, possa ser um instrumento transformador da realidade dos apenados. Segue entendimento de Onofre e Julião $(2013$, p. 63) sobre o assunto:

A educação deve se fazer presente em todos os espaços, como um sistema e não como um programa compensatório - nesse sentido, não se trata de uma educação especial e nem de segunda categoria. A qualidade é um quesito que deve primar em todos os espaços, pois se trata de um direito.

No Brasil, os números refletem que o sistema prisional não apresenta respostas boas para a sociedade, tampouco para os apenados. Os índices de ressocialização são baixos, os de reincidência são altos (estimados em $80 \%$ ) e os de violência e criminalidade, dentro dos presídios, também são elevados. Apresenta-se, ainda, crescimento assustador da população prisional brasileira, já sendo a terceira maior do mundo e, dentre as quatro maiores do mundo, a única que apresenta crescimento desta população em números gerais entre os anos de 2008 e 2014 (BRASIL, 2014).

Em regra, portanto, além de não apresentar boas respostas para o problema de como agir com os apenados e buscar fornecer instrumento para que possa ocorrer sua "reintegração social", as instituições prisionais sequer conseguem manter um ambiente sem violência, guerra de faç̧ões e/ou intensa atuação na seara do tráfico de entorpecentes.

Considerando este contexto, conclui-se que não é fácil a tarefa de constituir e efetivar um processo educativo no contexto de privação de liberdade comprometido com a dignidade da pessoa humana e que busque o desenvolvimento do indivíduo, indo ao encontro de alguns dos próprios objetivos/princípios da educação, conferindo um tratamento mais humano e digno à pessoa que se encontra na condição de apenado.

Uma das problemáticas relacionadas à temática é o necessário rompimento paradigmático no que se refere à forma como se encara o sistema prisional e o próprio apenado, devendo-se alterar o discurso e o pensamento vingativo e meramente punitivo, passando-se a pensar e tratar o assunto com mais humanidade, acompanhando, inclusive, o atual caráter da pena e do próprio Direito Penal, que objetiva a reintegração social.

Sobre isso, ainda na década de 70, Foucault (1999) destaca que, dentre os princípios fundamentais que regulam a prisão, existem sete máximas universais da boa "condição penitenciária", e uma delas seria justamente a questão educativa do apenado por parte do Estado, seja como precaução nos interesses da sociedade ou como direito do apenado. Destaca Foucault (1999, p. 297):

(...) 5) A educação do detento é, por parte do poder público, ao mesmo tempo uma precaução indispensável no interesse da sociedade e uma obrigação para com o detento.

Só a educação pode servir de instrumento penitenciário. A questão do encarceramento penitenciário é uma questão de educação (Ch. Lucas, 1838). O tratamento infligido ao prisioneiro, fora de qualquer promiscuidade corruptora deve tender principalmente à sua instrução geral e profissional e à sua melhora (Princípio da educação penitenciária).

O direito social dos apenados, portanto, será respeitado apenas no momento em que o Estado, ciente de seu dever de fornecer educação, estruturar e ofertar projetos educacionais para os mesmos, proporcionando educação de qualidade e verdadeiramente emancipatória. 
É neste aspecto que o processo educativo pode ser um instrumento de transformação da realidade, que é a de um sistema prisional falido, apresentando crescente número geral de apenados, altos índices de reincidência no cometimento de crimes e poucas alternativas e possibilidades de mudança no panorama das vidas dos egressos do sistema carcerário.

Entende-se que, ao romper esta situação e modificar o sistema prisional, cumprindo-se com o que prevê a legislação pertinente ao tema, possibilitando aos apenados o acesso à educação, efetivamente poder-se-á falar em uma possibilidade de reintegração social e diminuição das taxas de reincidência no cometimento de crimes, diminuindo-se a desigualdade social e a violência em nossa sociedade.

\section{CONSIDERAÇÕES FINAIS}

De acordo com o ordenamento jurídico vigente, o Estado atua na condição de responsável pelo "poder-dever" de processar, julgar e garantir o cumprimento de eventual pena atribuída a quem transgrediu a lei. $\mathrm{Na}$ medida em que o Estado tem sob sua tutela um cidadão na condição de apenado, porém, adquire responsabilidades para com o mesmo. Para nortear estas condições que lhe são atribuídas, o Estado se utiliza da Constituição Federal, do Direto Penal, do Código de Processo Penal e da legislação extravagante. ${ }^{1}$

É pertinente observar que o regramento jurídico enfrenta frequente evolução e/ou modificação, pois o mesmo representa e está de acordo com os fatos sociais, costumes, cultura, os quais, como é sabido, vão se transformando com o transcurso temporal. É por esta razão que o Direito não é uma ciência estanque, e, com o passar dos anos, as leis vão se modificando para se adequar aos novos costumes/princípios.

Em que pese existirem, todavia, as referidas modificações, isso não significa que os problemas e os conflitos existentes entre os códigos, as leis e a vida em sociedade sejam resolvidos. Além disso, é imprescindível ressaltar que as alterações devem estar em consonância com o texto legal promulgado pela Constituição Federal vigente, que é a de 1988, bem como com os princípios e garantias constitucionais, os quais funcionam "como um norte" a ser observado pelos operadores do direito, sendo uma defesa do cidadão e um limite para o Estado, na promulgação de novas leis e julgamento de demandas.

No Brasil vige o Estado Democrático de Direito, que detém como característica, ao menos na teoria, o respeito à democracia, devendo-se assegurar os direitos e garantias fundamentais que estão previstos na Constituição Federal a todos os cidadãos brasileiros que porventura venham a enfrentar algum processo.

No princípio do direito penal normativo, vigia a ideia central da pena com caráter meramente punitivo, sem qualquer referência a direitos e garantias fundamentais. Com o transcurso temporal e a mudança dos hábitos culturais, no entanto, sobreveio um caráter, ao menos na teoria, mais humano para a seara criminal e no tratamento ao acusado. No Brasil, com a promulgação da Constituição Federal vigente, os direitos humanos e as garantias fundamentais receberam importante respaldo, pois se enquadram como cláusulas pétreas, sobrepondo-se, por conseguinte, a qualquer norma ou lei que as contrarie.

Constatam-se, como alguns dos requisitos para a configuração de um Estado Democrático de Direito, a existência e o respeito aos princípios da dignidade da pessoa humana, igualdade e legalidade. Neste sentido, o sistema e o processo penal, da mesma forma, devem estar em compasso com os referidos princípios, uma vez que, como destacado, os mesmos estão na ordem de cláusulas pétreas.

É notória a crise que assola o sistema prisional brasileiro. Entende-se que a educação detém grande relevância quando aplicada como uma das possibilidades de reintegração social do apenado, e pode ser um dos caminhos para transformar a realidade vigente no sistema prisional brasileiro, que é a de um sistema falido e que não confere tratamento digno e humano às pessoas que estão sob tutela do Estado, a fim de que o apenado possa se (re)integrar na sociedade no momento em que readquirir sua liberdade.

Sabe-se que existe mais de uma possibilidade de tentar a reintegração social do apenado a fim de obter sua reintegração social, porém entende-se que a educação é a que detém o poder de sensibilizar o apenado, promovendo reflexões de ordem moral e também qualificação profissional, configurando-se como uma oportunidade fundamental e de singular importância.

Trata-se de leis que abordam o tema, mas que não estão inseridas no Código Penal. 
Assim, num país que se intitula como sendo um Estado Democrático de Direito, é inconcebível negar o acesso à educação a qualquer pessoa, considerando que isto ofende diversos princípios, como o da isonomia e o da dignidade da pessoa humana. Além disso, a própria Constituição Federal e a Lei de Execuções Penais resguardam o acesso a todos ao ensino, definindo-o como um direito público subjetivo de todos.

Resta claro, por conseguinte, que se deve proporcionar o acesso e a permanência em processos educativos para os apenados, principalmente em nível superior, posto que, com esta formação, se obtém um diferencial quando progredir para o regime de liberdade. Isto deverá ser concretizado mediante políticas públicas voltadas para esta finalidade.

Diante de todo o exposto, condensa-se o resultado em algumas conclusões:

1 - No Estado Democrático de Direito a Constituição Federal e a Lei de Execuções Penais são precisas e definem como dever do Estado proporcionar, a todos, o direito à educação fundamental e média.

2 - É dever da Administração Pública disciplinar meios e projetos educacionais adequados com a realidade de vida do apenado, objetivando manter sua motivação e demonstrar a pertinência na participação dos processos educativos prisionais que deverão ser institucionalizados.

3 - O Estado não trata a educação de pessoas privadas de liberdade como política pública, o que gera diversos problemas, principalmente a falta de amparo e apoio às iniciativas isoladas que objetivam institucionalizar processos educativos.

O direito social dos apenados apenas estará resguardado no momento em que o Estado, ciente de seu dever de lhes proporcionar acesso e frequência à educação, cumpra a lei por meio de uma política pública voltada para esta finalidade.

Perante o cenário exposto sobre o tema, sustenta-se que se torna imprescindível que advenha uma política pública destinada à educação desta população prisional como uma das possibilidades de se obter sua reintegração social, principalmente pelo fato de que a referida população é jovem, com baixa escolaridade, com altos índices de reincidência criminal e apresenta número significativo e crescente, sendo um retrato de um país com tamanha concentração de renda e desigualdade como o Brasil.

\section{REFERÊNCIAS}

ARBAGE, Lucas Andres; DA COSTA VASCONCELLOS, Rodrigo. Educação de jovens e adultos privados de liberdade na América Latina: uma alternativa de (re)começo.Prim@ Facie-Direito, História e Política, v. 16, n. 33, p. 1-45, 2017.

ASSIS, R. D. A realidade atual do sistema penitenciário brasileiro. Revista CEJ, Brasília, DF, v. 11, n. 39, p. 74-78, 2007.

BARATTA, Alessandro. Ressocialização ou controle social: uma abordagem crítica da "reintegração social" do sentenciado. In: SEMINÁRIO CRIMINOLOGÍA CRÍTICA Y SISTEMA PENAL, 1990, Lima. Anais [...]. Lima: Comissão Andina Juristas, Comissão Episcopal de Ação Social, set. 1990.

BRASIL. Departamento Penitenciário Nacional. Levantamento nacional de informações penitenciárias - INFOPEN. 2014. Disponível em: http://www.justica.gov.br/seus-direitos/politica-penal/transparencia-institucional/estatisticas-prisional/levantamento-nacional-de-informacoes-penitenciarias. Acesso em: 13 abr. 2018.

BRASIL. Departamento Penitenciário Nacional. Levantamento Nacional de Informações Penitenciárias - INFOPEN. 2017. Disponível em: http://www.justica.gov.br/news/ha-726-712-pessoas-presas-no-brasil/relatorio_2016_junho.pdf/view. Acesso em: 13 abr. 2018.

BRASIL. Constituição 1988. Constituição da República Federativa do Brasil. Diário Oficial da União, Brasília, DF, 5 out. 1988. Disponível em: http://www.planalto.gov.br/ccivil_03/Constituicao/Constituicao.htm. Acesso em: 11 mar. 2018.

BRASIL. Decreto-Lei 2.848, de 7 de dez. de 1940. Código Penal. Diário Oficial da União, Rio de Janeiro, 31 dez. 1940. Disponível em: http://www.planalto.gov.br/ccivil_03/decreto-lei/Del2848compilado.htm. Acesso em: 11 mar. 2018.

BRASIL. Lei no 12.343, de 29 de junho de 2011. Altera a Lei no 7.210, de 11 de julho de 1984 (Lei de Execução Penal), para dispor sobre a remição de parte do tempo de execução da pena por estudo ou por trabalho. Diário Oficial da União, Brasília, DF, 29 de junho de 2011. Disponível em: http://www.planalto.gov.br/ccivil_03/_ato2011-2014/2011/lei/l12433.htm. Acesso em: 11 mar. 2018.

BUCCI, Maria Paula Dallari (org.). Políticas públicas: reflexões sobre o conceito jurídico. São Paulo: Saraiva, 2006.

CURY, Carlos R. J. A educação básica no Brasil. Revista Educação \& Sociedade, Campinas, v. 23, n. 80, p. 168-200, set. 2002.

CURY, Carlos Roberto Jamil. O direito à educação: um campo de atuação do gestor educacional na escola. Brasília: Escola de Gestores, 2005. 
DATAFOLHA. 10 Anuário Brasileiro de Segurança Pública. Disponível em: http://www.forumseguranca.org.br/storage/download//anuario-2016-03nov-final.pdf. Acesso em: 1 maio 2017.

DARKE, Sacha; KARAM, Maria. Prisões Latino Americanas (Prisões da América Latina) (2016). 'Prisões latino-americanas', emporiododireito. Disponível no SSRN: https://ssrn.com/abstract=2810994.

FELBERG, Rodrigo. A reintegração social dos cidadãos egressos, uma nova dimensão de aplicabilidade das ações afirmativas. 2013. Tese (Doutorado em Direito) - Universidade Presbiteriana Mackenzie, São Paulo, 2013.

FREIRE, Paulo. Pedagogia do oprimido. 35. ed. São Paulo: Paz e Terra, 2003.

FOUCAULT, Michel. Vigiar e punir: nascimento da prisão. 20. ed. Petrópolis: Vozes, 1999.

GIMENEZ, María Eugenia Bové. Coerción y libertad: la educación en cárceles. un estudio de caso en una cárcel de mujeres de Uruguay. 2015. Dissertação (Mestrado em Estudos Políticos e Sociais) - Universidad Nacional Autónoma de México, 2015.

IRELAND, T. D. Educação em prisões no Brasil: direito, contradições e desafios. Em Aberto, Brasília, v. 24, n. 86, p. 19-39, nov. 2011. (Dossiê Educação em prisões, organizado por T. D. Ireland).

JULIÃO, Elionaldo Fernandes. The impact of education and work as programmes for social reinsertion on the policy of penal execution in Rio de Janeiro. Revista Brasileira de Educação, v. 15, n. 45, p. 529-543, 2010.

LACERDA, Heliane Gomes. Políticas de restrição e privação da liberdade implementada na Colômbia, Niterói-RJ. 2016. Trabalho de Conclusão de Curso (Graduação em Ciências Sociais) - Universidade Federal Fluminense, Instituto de Ciências Humanas e Filosofia, Departamento de Ciências Sociais, 2016.

MAEYER, Marc de. Na prisão existe perspectiva da educação ao longo da vida? Alfabetização e cidadania: Revista Brasileira de Educação de Jovens e Adultos, Brasília: RAAAB, Unesco, Governo Japonês, n. 19, p. 17-37, jul. 2006.

MAEYER, Marc de. Ter tempo não basta para que alguém se decida aprender. Em Aberto, Brasília, v. 24, n. 86, p. 43-55, nov. 2011. (Dossiê Educação em prisões, organizado por T. D. Ireland).

MAEYER, Marc de. A educação na prisão não é uma mera atividade. Educação \& Realidade, Porto Alegre, v. 38, n. 1, p. 33-49, jan./mar. 2013.

ONOFRE, Elenice Maria Cammarosano. Education for youth and adults in situations of deprivation of liberty. Cadernos Cedes, v. 35, n. 96, p. 239-255, 2015.

ONOFRE, Elenice Maria Cammarosano; JULIÃO, Elionaldo Fernandes. A educação na prisão como política pública: entre desafios e tarefas. Educação \& Realidade, v. 38, n. 1, 2013.

PEREIRA, Antonio. A educação-pedagogia no cárcere, no contexto da pedagogia social: definições conceituais e epistemológicas. Revista de Educação Popular, v. 10, 2011.

RANGEL, Hugo. Mapa regional latino-americano sobre educación en prisiones: notas para el análisis de la situación y la problemática regional. Paris: Centre International D’Études Pédagogiques (CIEP), 2009.

RANGEL, Hugo. Educación contra corriente en las cárceles latinoamericanas: la enseñanza vs el castigo. Revista Educação e Realidade, Porto Alegre, v. 38, p. 15-32, jan./mar. 2013.

SÁ, Alvino Augusto de. Criminologia clínica e psicologia criminal. São Paulo: Editora Revista dos Tribunais, 2007.

SCARFÓ, Francisco José. Educación Pública de Adultos en las Cárceles: garantía de un derecho humano. Revista Decisio, México: Centro de Cooperación Regional para la Educación de Adultos en América Latina y el Caribe, n. 14, p. 21-25, maio/ago. 2006. Disponível em: http://www.gesec.com.ar/publicaciones/. Acesso em: 11 mar. 2018.

SCARFÓ, Francisco; LALLI, Florencia Pérez; MONTSERRAT, Ivana. Avances en la Normativa del Derecho a la Educación en Cárceles de la Argentina. Educação \& Realidade, v. 38, n. 1, 2013.

SILVA, Mazukyevicz Ramon Santos do Nascimento. A dimensão cultural da educação em prisões. 2016. 458f. Tese (Doutorado em Ciências Jurídicas) - Universidade Federal da Paraíba, João Pessoa, 2016.

SILVA, Mazukyevicz Ramon Santos do Nascimento; BRAGA, Romulo Rhemo Palitot. Segurança Pública e Direitos Humanos: o que pode a educação na prisão? Prima Facie-Direito, História e Política, v. 10, n. 18, p. 345-378, 2011.

SILVA, Roberto. A eficácia sociopedagógica da pena de privação da liberdade. Educação e Pesquisa, v. 41, n. 1, 2015.

SILVA, Roberto da; MOREIRA, Fábio Aparecido. Objetivos educacionais e objetivos da reabilitação penal: o diálogo possível. Revista Sociologia Jurídica, Dossiê Questões Penitenciárias, n. 3, jul./dez. 2006.

ZAGURSKI, Adriana Timoteo dos Santos; KRUBNIKI, João Pedro Ruppert. Breves apontamentos sobre estado social e intervenção mediante políticas públicas. Revista Direito em Debate, [S.I.], v. 26, n. 47, p. 113-132, set. 2017. ISSN 2176-6622. Disponível em: https://www.revistas.unijui.edu.br/index.php/revistadireitoemdebate/article/view/5823. Acesso em: 23 abr. 2018. DOI: https://doi.org/10.21527/2176-6622.2017.47.113-132. 